\title{
Inferior Epigastric Artery Injury Following Blunt Trauma Treated by Catheter Embolization
}

\section{Brendan Morrissey ${ }^{1 *}$, Mark Harmon ${ }^{2}$, Niall McEniff ${ }^{3}$ and Geraldine McMahon C $^{4}$}

${ }^{1}$ Emergency Registrar, St James' Hospital, Dublin 8, Ireland

${ }^{2}$ Specialist Registrar in Radiology, St. James's Hospital, Dublin 8, Ireland

${ }^{3}$ Consultant Interventional Radiologist, St James's Hospital, Dublin 8, Ireland

${ }^{4}$ Consultant and Senior Lecturer in Emergency Medicine, Emergency Department, St James's Hospital, Dublin 8, Ireland

Keywords: Inferior epigastric artery; Blunt trauma; Interventional radiology; Catheter angiography

\section{Introduction}

Inferior Epigastric Artery Injury (IEAI) following blunt trauma is a rare but potentially life-threatening condition. IEAI most commonly occurs as an iatrogenic injury (paracentesis, percutaneous drain, and laparoscopy) [1-4]. Not surprisingly there is an increased incidence of IEAI in patients with end-stage liver disease and coagulopathy [57]. Non-iatrogenic injury is generally associated with penetrating or high-velocity blunt trauma e.g. complicating seatbelt injuries [8-10]. We present a case of an injury to the pubic branch of the inferior epigastric artery following a low velocity fall in an older patient fully anti-coagulated on warfarin for pre-existing pulmonary emboli.

\section{Case Report}

An 80-year-old female presented to our Emergency Department (ED) one hour after a simple mechanical fall from standing at home onto her left side. She was transferred by ambulance to ED with severe left hip pain. Information from the paramedic crew indicated she had suffered repeated pre-syncopal episodes secondary to self-limiting transient episodes of hypotension en route to hospital.

She was hypotensive, pale and clammy on arrival in ED. Physical examination revealed tenderness in the left groin but was otherwise unremarkable. There was no shortening or external rotation of her left hip. Initial pelvic x-rays revealed no obvious fracture. She continued to suffer recurrent pre-syncopal episodes associated with transient hypotension. Serial hemoglobin measurements revealed a significant drop ( $11.8 \mathrm{~g} / \mathrm{dL}$ to $9.4 \mathrm{~g} / \mathrm{dL}$ over 4 hours). She was treated with IV vitamin $\mathrm{K}$, Prothrombin Complex and fluid resuscitation and blood transfusion (7 units). A trauma protocol CT abdomen and pelvis was performed with imaging in the arterial, portal venous and delayed phases. This revealed a large pelvic hematoma with active contrast extravasation in the arterial phase consistent with ongoing acute arterial hemorrhage. The source vessel was not identified, but the active extravasation was adjacent to a non-displaced fracture of the left superior pubic ramus and body (Figure 1). As this was the obvious source of her hemodynamic instability she was transferred to the interventional radiology suite for embolization. The right femoral artery was catheterized. Selective angiography of the left anterior and posterior divisions of the internal iliac artery using 5Fr Roberts Uterine Catheter did not identify a bleeding point. AP and $25^{\circ}$ oblique projections were obtained. Subsequently, a left external iliac angiogram demonstrated active contrast extravasation within the pelvis. Subselective catheterization using a 0.014 guide wire and a 2.7Fr FasTracker microcatheter (Boston Scientific) revealed the pubic branch of the inferior epigastric artery as the bleeding vessel. The bleeding vessel was too small to accommodate the microcatheter, so the proximal inferior epigastric artery was successfully embolized using microcoils (Figure 2). Three $3 \times 2 \mathrm{~mm}$ and two $4 \times 2 \mathrm{~mm}$ Tornado Microcoils (Cook Medical) were used to embolise the left inferior epigastric artery proximal and distal to origin of the bleeding pubic branch. The patient stabilized hemodynamically following the procedure and was transferred to the intensive care unit for monitoring overnight. She made an uncomplicated recovery and was discharged home 12 days later. On routine follow-up in Vascular Out-Patient Clinic six weeks later she remained well and was discharged to the care of her General Practitioner.

\section{Discussion}

The inferior epigastric artery originates from the external iliac artery, running between the abdominal peritoneum and the rectus muscles, medial to the deep inguinal ring. It terminates in to numerous branches, which anastomose with the superior epigastric and lower intercostal arteries above the level of the umbilicus. The pubic branch

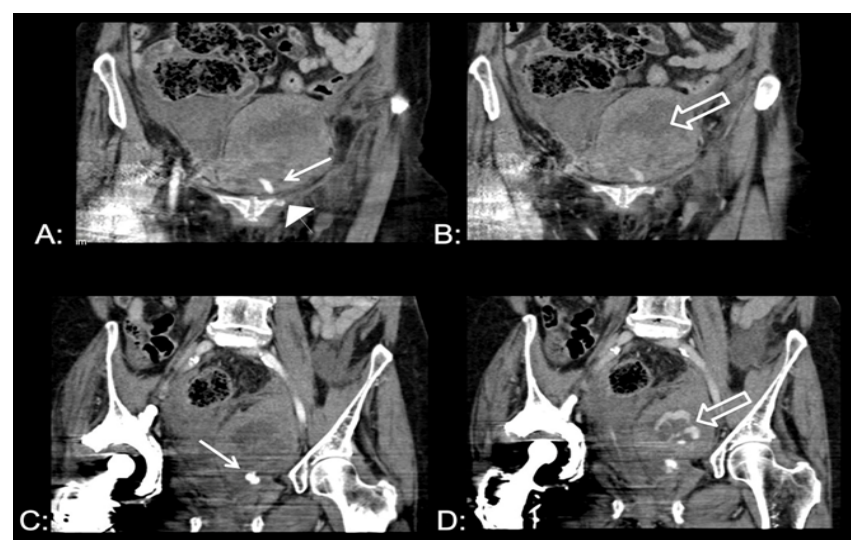

Figure 1: Coronal $C T$ in the arterial $(A$ and $C)$ and venous $(B$ and $D)$ phases demonstrating acute arterial haemorrhage (white arrow) into a large pelvic haematoma (white open arrow) adjacent to a left public fracture (white arrow head in $(A))$.

*Corresponding author: Brendan Morrissey, MB BCh BAO, Emergency Registrar St James' Hospital, Dublin 8, Ireland, Tel: 00675 71412522; Fax: +353 (0) 1410 3451; E-mail: brendanmorrissey81@gmail.com

Received November 01, 2013; Accepted January 23, 2014; Published January 25, 2014

Citation: Morrissey B, Harmon M, McEniff N, Geraldine McMahon C (2014) Inferio Epigastric Artery Injury Following Blunt Trauma Treated by Catheter Embolization J Vasc Med Surg 2: 124. doi: 10.4172/2329-6925.1000124

Copyright: (C) 2014 Morrissey B, et al. This is an open-access article distributed under the terms of the Creative Commons Attribution License, which permits unrestricted use, distribution, and reproduction in any medium, provided the original author and source are credited. 
of the inferior epigastric artery arises proximally and courses along the inguinal ligament and descends to the internal surface of the pubis, where it sometimes anastomoses with branches from the obturator artery. If this connection between the external iliac system and the obturator system exists, it is termed the corona mortis, which translated means "connection of death". This is due to the severe bleeding that can develop if these vessels are cut and the difficulty that can exist in achieving hemostasis.

IEAI is a rare but potentially fatal injury. One retrospective review of IEAI cases [5] (presenting to the interventional radiology departments of three university-affiliated hospitals in California, USA) revealed only 20 cases over a 12 -year period, with a 30 -day mortality rate of $30 \%$.

Previous studies of significant intra-abdominal vascular injuries presenting to $\mathrm{ED}[5,8,11,12]$ reveal a preponderance of penetrating $(>80 \%)$ trauma as the etiology. Blunt abdominal trauma resulting in significant vascular injury is most commonly associated with high velocity Road Traffic Collisions (RTC) [12]. These injuries are rarely

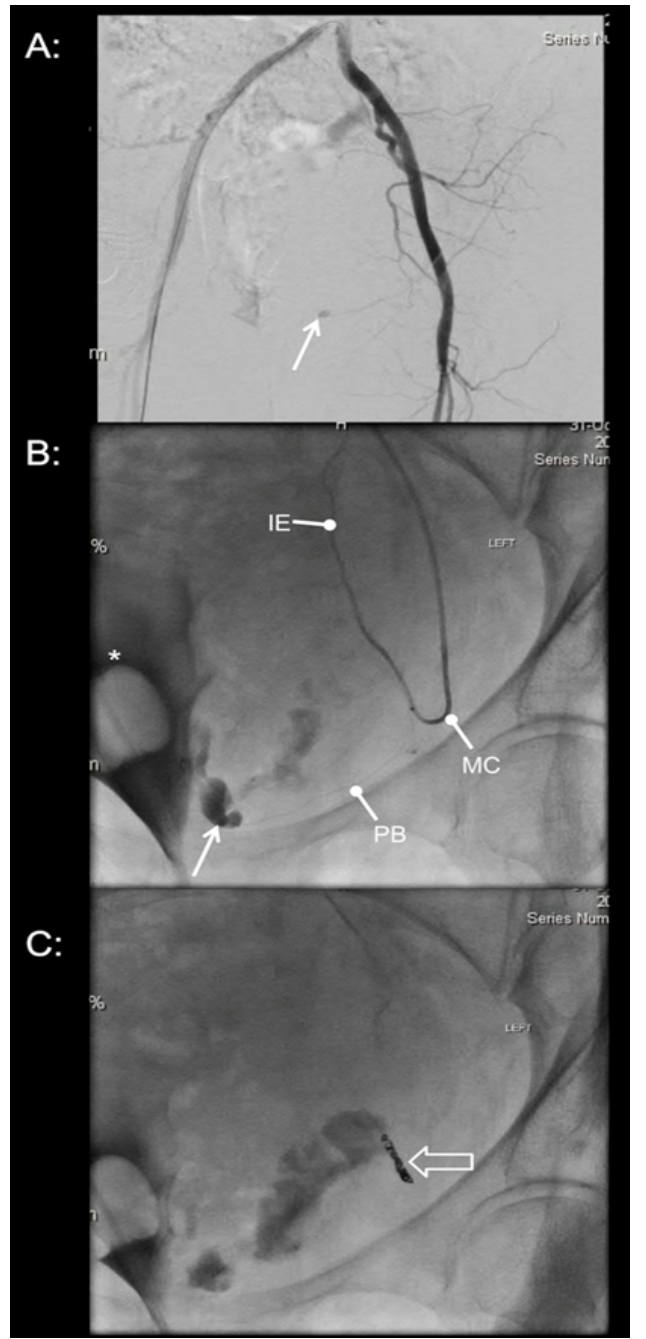

Figure 2: A: Left common iliac artery angiogram showing an arterial extravasation (white arrow) in the pelvis. B: Subselective catheterization of the inferior epigastric artery (IE) with a microcatheter (MC) demonstrates acute haemorrhage (white arrow) from the distal public branch (PB). The bladder $\left(^{*}\right)$ contains a urinary catheter and is displaced. isolated, frequently co-existing with solid organ and bony injuries [912]. Low impact IEAI is extremely rare, but injury to the pubic branch of the inferior epigastric artery can be associated with isolated pubic ramus fractures, especially in patients receiving anticoagulation $[13,14]$.

Multiphase multi-detector row CT is now the investigation of choice for suspected pelvic vascular injury [15-17]. This has the benefit of assessing for concomitant bony, visceral or vascular injuries and proves invaluable in determining the need for conservative, operative or percutaneous management. In cases where CT angiography is contraindicated the use of Doppler ultrasound and red blood cell scintigraphy [18] have also been described.

Management of active inferior epigastric artery hemorrhage is broadly divided between surgery and interventional radiology. In the case of intra-operative iatrogenic injury, surgical management (balloon tamponade, electrocoagulation, transabdominal sutures) may be the approach of choice as the quickest method of controlling hemorrhage. Outside of the operating theatre, however, interventional radiology provides a rapid, proven approach to regaining hemostasis in such patients, with a success rate of up to $90 \%$ [5]. In this case, the bleeding vessel itself was too small to accommodate a microcatheter, therefore particle embolization was not used because of the risk of end-organ tissue necrosis and non-target embolization. Instead, microcoils were used to embolise the left inferior epigastric artery proximal and distal to the origin of the pubic branch, thus 'closing the front and back entrance' into the vessel. The coils were also extended over the origin of the bleeding vessel. The left internal iliac angiogram performed initially had excluded significant collateralization from the obturator vessels. Contralateral angiograms were not required as the patient stabilized immediately following embolization of the bleeding vessel. Although there is a well-documented collateral supply to the pubic branch of the inferior epigastric artery from the obturator vessels, contralateral collaterals are generally less well developed. Timely reversal of any concomitant coagulopathy should also be prioritized.

In conclusion, IEAI is a rare but potentially life-threatening condition. Although it is most commonly associated with iatrogenic or high-velocity trauma, the pubic branch of the inferior epigastric artery can be avulsed by a non-displaced pubic fracture following a low-impact fall. A physician's index of suspicion should be raised by hemodynamic compromise in the presence of underlying coagulopathy, especially in the older patient. IEAI requires prompt diagnosis and urgent intervention if a poor outcome is to be prevented. Multiphase $\mathrm{CT}$ is the investigation modality of choice allowing for assessment and differentiation of active arterial or venous hemorrhage and the assessment of concomitant visceral injury. Catheter angiography and embolization is an accepted first-line choice for interventional management of inferior epigastric artery hemorrhage. If the pubic branch is the source of bleeding, internal iliac angiography should also be performed to exclude anastomosis with the obturator artery.

\section{References}

1. Lavery S, Porter S, Trew G, Margara R, Jackson J (2006) Use of inferio epigastric artery embolization to arrest bleeding at operative laparoscopy. Fertil Steril 86: 719 .

2. Segev $Y$, Orron D, Alon R, Graif M (1994) Pseudoaneurysm of the inferior epigastric artery mimicking abdominal wall hematoma. J Ultrasound Med 13: 483-484.

3. Lam EY, McLafferty RB, Taylor LM Jr, Moneta GL, Edwards JM, et al. (1998) Inferior epigastric artery pseudoaneurysm: a complication of paracentesis. $J$ Vasc Surg 28: 566-569. 
Citation: Morrissey B, Harmon M, McEniff N, Geraldine McMahon C (2014) Inferior Epigastric Artery Injury Following Blunt Trauma Treated by Catheter Embolization. J Vasc Med Surg 2: 124. doi: 10.4172/2329-6925.1000124

4. Shabani AG, Baxter GM (2002) Inferior epigastric artery pseudoaneurysm: ultrasound diagnosis and treatment with percutaneous thrombin. $\mathrm{Br} \mathrm{J}$ Radiol 75: 689-691.

5. Sobkin PR, Bloom Al, Wilson MW, LaBerge JM, Hastings GS, et al. (2008) Massive abdominal wall hemorrhage from injury to the inferior epigastric artery: a retrospective review. J Vasc Interv Radiol 19: 327-332.

6. Runyon BA (1986) Paracentesis of ascitic fluid. A safe procedure. Arch Intern Med 146: 2259-2261.

7. Lin $\mathrm{CH}$, Shih FY, Ma MH, Chiang WC, Yang CW, et al. (2005) Should bleeding tendency deter abdominal paracentesis? Dig Liver Dis 37: 946-951.

8. Asensio JA, Chahwan S, Hanpeter D, Demetriades D, Forno W, et al. (2000) Operative management and outcome of 302 abdominal vascular injuries. Am J Surg 180: 528-533.

9. Brown JJ, Greene FL, McMillin RD (1984) Vascular injuries associated with pelvic fractures. Am Surg 50: 150-154.

10. Yoon W, Kim JK, Jeong YY, Seo JJ, Park JG, et al. (2004) Pelvic arteria hemorrhage in patients with pelvic fractures: detection with contrast-enhanced CT. Radiographics 24: 1591-1605.

11. Drapanas T, Hewitt RL, Weichert RF 3rd, Smith AD (1970) Civilian vascular injuries: a critical appraisal of three decades of management. Ann Surg 172: $351-360$
12. Peitzman Andrew $B$, Rhodes Michael, Schwab $C$ William, Yealy Donald $M$ Fabian Timothy C (2002) Trauma Manual (2ndedn). Lippincott Williams \& Wilkins, USA.

13. Lu CK, Lee YC, Sun PL, Liang CL, Liliang PC (2010) Life threatening bleeding from the pubic branch of inferior epigastric artery after pubic ramus fracture. Hong Kong Journal of Emergency Medicine 17: 372-376.

14. Meyers TJ, Smith WR, Ferrari JD, Morgan SJ, Franciose RJ, et al. (2000) Avulsion of the pubic branch of the inferior epigastric artery: a cause of hemodynamic instability in minimally displaced fractures of the pubic rami. Trauma 49: 750-753.

15. Cherry WB, Mueller PS (2006) Rectus sheath hematoma: review of 126 cases at a single institution. Medicine (Baltimore) 85: 105-110.

16. Anderson SW, Soto JA, Lucey BC, Burke PA, Hirsch EF, et al. (2008) Blunt trauma: feasibility and clinical utility of pelvic CT angiography performed with 64-detector row CT. Radiology 246: 410-419.

17. Hamilton JD, Kumaravel M, Censullo ML, Cohen AM, Kievlan DS, et al. (2008) Multidetector CT evaluation of active extravasation in blunt abdominal and pelvic trauma patients. Radiographics 28: 1603-1616.

18. Wilson MW, Fidelman N, Lull RJ, Marder SR, Laberge JM, et al. (2002) Evaluation of active bleeding into hematomas by technetium-99m red blood cell scintigraphy before angiography. Clin Nucl Med 27: 763-766. 